\title{
Probit structural equation regression model: general depressive symptoms predicted post-myocardial infarction mortality after controlling for somatic symptoms of depression
}

\author{
Brett D. Thombs ${ }^{\mathrm{a}, *}$, Roy C. Ziegelstein ${ }^{\mathrm{b}}$, Kapil Parakh ${ }^{\mathrm{b}}$, Donna E. Stewart ${ }^{\mathrm{c}, \mathrm{d}}$, \\ Susan E. Abbey ${ }^{c, d}$, Sherry L. Grace ${ }^{c, d, e}$
}

\begin{abstract}
Objective: Reported links between depression and post-acute myocardial infarction (AMI) mortality may be due to confounding between somatic symptoms of depression and symptoms related to the AMI. The objective of this study was to assess the relationship between depressive symptoms and 12-month post-AMI mortality after removing potential bias from somatic symptoms of depression.

Study Design and Setting: Four hundred seventy-seven hospitalized AMI patients from 12 cardiac care units. The relationship of a General Depression factor with mortality was assessed using a probit structural equation regression model, controlling for an uncorrelated somatic symptom factor, age, Killip class, previous AMI, and other potential confounders.

Results: Mortality was significantly predicted by the General Depression factor $(P=0.009)$, controlling for age $(P=0.128)$, Killip class $(P=0.210)$, history of AMI $(P=0.001)$, and other predictors in a structural equation model that removed variance related to somatic factors, but unrelated to the General Depression factor.

Conclusion: This study demonstrated that the use of structural equation modeling presents a viable mechanism to test links between symptoms of depression and health outcomes among patients with AMI after explicitly removing variance due to somatic symptoms that is unrelated to the General Depression factor.
\end{abstract}

Keywords: Myocardial infarction; Mortality; Depression; Assessment; Beck Depression Inventory; Confirmatory factor analysis

\section{Introduction}

Numerous studies have found that symptoms of depression are related to increased risk of mortality following acute myocardial infarction (AMI) after controlling for demographic and disease severity variables [1-4], although not all studies have reported a significant association [5,6]. Several recent systematic reviews or meta-analyses of the independent association between post-AMI depression and mortality have concluded that unambiguous conclusions could not be reached because of incomplete control for confounding [7-9]. The authors of one of the reviews [7] and others [3,10-12] have argued that existing studies linking depression to cardiac and all-cause mortality post-AMI have not adequately controlled for confounding in measurement of depressive symptoms related to overlap between somatic symptoms of depression and cardiac symptoms. Indeed, symptoms characteristically associated with depression, such as fatigue, anhedonia, changes in sleep patterns, changes in appetite, or poor concentration, for instance, could occur as a normal reaction to the AMI, from side effects of its treatment, or from the hospitalization itself $[13,14]$. The BDI is the most commonly used method to screen for symptoms of depression among post-AMI patients [15], and specific concerns have been raised about its validity in medical patients because six of 21 items assess somatic symptoms [16-20].

It is important to be able to accurately distinguish somatic symptoms related to depression from nondepressive somatic symptoms. Clinically, bias in the assessment of depressive symptoms could result in the overidentification of patients with the most severe AMIs as depressed. In outcomes 


\section{What is New?}

- Structural equation modeling (SEM) methods can be used to model a General Depression factor free of variance from somatic symptoms that are unrelated to depression, but including variance from somatic symptoms that are related to depression.

- This methodology is useful to assess the independent contribution of depressive symptoms to important outcomes free of bias from somatic symptom overlap.

- In a sample of 477 post-acute myocardial infarction (AMI) patients, the General Depression factor predicted mortality 12 months post-AMI, controlling for somatic symptoms unrelated to depression per se.

- Future studies should incorporate SEM methods to assess the independent association of depressive symptoms with important outcomes and should include greater coverage of cardiac risk variables than were available in this study.

research, bias could lead to artifactual links between symptoms of depression and post-AMI morbidity and mortality. Structural equation modeling (SEM) techniques present an alternative to traditional regression models that allows for the possibility of explicitly separating variance related to depression per se and variance related to extraneous somatic factors through the use of latent variables. Ward [21] recently published a confirmatory factor analysis (CFA) model for the Beck Depression Inventory (BDI)-II that explicitly separated variance from a General Depression factor from variance from unrelated somatic symptoms. Ward demonstrated in five different samples that a BDI-II model with orthogonal General Depression, Somatic, and Cognitive factors (G$\mathrm{S}-\mathrm{C})$ fit as well or better than previously published correlated-factor models. In Ward's model, all BDI-II item scores are indicators of the General Depression factor, and some items also load on Somatic or Cognitive factors that are orthogonal to the General Depression factor and each other.

Although Ward's model is a promising alternative, most post-AMI research continues to use the original BDI rather than the revised BDI-II. Many items on the BDI and BDI-II are equivalent, but six of 21 items are not. Thus, the objectives of this study were (1) to develop a $\mathrm{G}-\mathrm{S}-\mathrm{C}$ model for the BDI in post-AMI patients and (2) to use the model to assess the relationship between the General Depression latent factor and mortality 12 months post-AMI after removing potential bias from somatic symptoms on the BDI.

\section{Methods}

\subsection{Patients and procedures}

Data were collected as part of a longitudinal study of depression after acute coronary syndromes (ACS). The methods of the study have been described previously [22]. Adult patients (18 years and older) who were diagnosed with a confirmed AMI or unstable angina (UA) were recruited in the coronary care unit $(\mathrm{CCU})$ by a research nurse on the 2 nd to 5 th day of the acute hospitalization. Patients were recruited from 12 CCUs in both large urban teaching hospitals and community hospitals in small- and medium-sized cities across Southcentral Ontario, Canada. Patients were excluded if they were medically unstable or unable to read or speak English. Patients who met study criteria and agreed to participate signed a consent form and were provided with a self-report questionnaire, which included the BDI. Questionnaires were also administered via mail at 6 months and 12 months post-AMI. All patients received standard aftercare for their ACS. The original study protocol was approved by the Research Ethics Boards of the University of Toronto and University Health Network. In-hospital data from AMI patients, but not UA patients, were included in the present analyses.

\subsection{Measure}

\subsubsection{Symptoms of depression}

The BDI [23] is a 21 -item measure of depressive symptoms. Each item consists of four statements, scored 0-3, indicating increasing symptom severity, and total scores range from 0 to 63 . Respondents are instructed to describe the way they have been feeling during the past week. The authors of the BDI recommend cutoff scores of $\geqslant 10$ for at least mild symptoms of depression [24], and this cutoff is typically used in studies of patients with AMI [15].

\subsubsection{Medical variables}

Killip class, measured on a four-point scale, was used to indicate the severity of the AMI by assessing the presence of heart failure at the time of the AMI. Killip class and history of previous AMI were determined from the medical record. Other health status variables, such as comorbidities and smoking status were determined from the patient health questionnaire.

\subsubsection{Mortality status}

The primary outcome variable was all-cause mortality within 12 months of discharge from the hospital. For patients who did not return 12-month follow-up questionnaires, vital status was determined by contacting by telephone, in sequence as necessary, patients, patients' family members or contacts listed in the initial data collection form, patients' general practitioners, and patients' specialist physicians.

\subsection{Data analyses}

Patient demographic and medical data were compared between patients who were alive 12 months post-AMI and patients who died during this period. Differences 
between the groups on categorical variables were assessed using the $\chi^{2}$ statistic and on continuous variables with two-tailed $t$-tests. Comparisons were conducted with SPSS version 15.0 (Chicago, IL, USA) with a significance level of $P<0.05$.

\subsubsection{CFA models}

Two CFA models were fit to the BDI data following the procedure used by Ward with the BDI-II [21]. First, the data were fit to the most commonly used BDI factor model, the three-factor Negative Attitudes-Performance Impairment-Somatic Disturbance model (NA-PI-SD) [24]. In the NA-PI-SD model, the items sadness, pessimism, past failure, guilty feelings, punishment feelings, self-dislike, self-blame, suicide ideation, and physical appearance load on the NA factor; the items loss of pleasure, irritability, loss of interest, indecisiveness, ability to work, fatigue, and health concerns load on the PI factor; and the items sleep problems, appetite, weight loss, and sexual disinterest load onto the SD factor. For the NA-PI-SD model, modification indices were used to identify pairs of items within factors for which model fit would improve if error estimates were freed to correlate, and for which there appeared to be theoretically justifiable shared method effects [25]. Based on modification indices, correlated errors were permitted between two items: ability to work and fatigue.

After fitting the NA-PI-SD model, an orthogonal $\mathrm{G}-\mathrm{S}-\mathrm{C}$ factor model similar to Ward's $\mathrm{G}-\mathrm{S}-\mathrm{C}$ model for the BDI-II was developed for the BDI. Consistent with Ward's procedure, all 21 items were specified to load on the General factor. In addition, six items were specified to load on the Somatic factor (ability to work, sleep problems, fatigue, appetite, weight loss, health concerns), eight items on the Cognitive factor ( pessimism, past failure, guilty feelings, punishment feelings, self-dislike, self-blame, suicidal thoughts, physical appearance), two items on a minor Self-Criticalness factor (self-dislike, self-blame), and two items on a minor Anhedonia factor (loss of pleasure, loss of interest). The pairs of items that loaded on each of the latter two factors were constrained to equality for model identification purposes. It is important to note that all items that loaded on the Somatic, Cognitive, Anhedonia, or Self-Criticalness factors also loaded on the General Depression factor. This is because the $\mathrm{G}-\mathrm{S}-\mathrm{C}$ model estimates the proportion of variance from a single item, such as fatigue, for example, that is related to depression and the proportion of variance in that item due to somatic factors unrelated to depression. For model identification purposes, each of the latent factors was specified to have a mean of 0 and a variance of 1 .

In addition to the main $\mathrm{G}-\mathrm{S}-\mathrm{C}$ model, a simplified $\mathrm{G}-\mathrm{S}-\mathrm{C}$ model that would allow for easier implementation in outcomes research was tested. This model did not include the minor Self-Criticalness and Anhedonia factors. For the $\mathrm{G}-\mathrm{S}-\mathrm{C}$ and simplified $\mathrm{G}-\mathrm{S}-\mathrm{C}$ models, item communalities $\left(h^{2} \mathrm{~s}\right)$ that represented the percent of variance in each item predicted by the factors were calculated from standardized factor loadings.

All CFA models were conducted with Mplus (version 3.11) [26], explicitly modeling the BDI items as ordinal data. A robust least square estimator was used to accommodate the ordinal BDI item data and the binary mortality outcome variable. Mplus provides adjusted mean and mean and variance-adjusted $\chi^{2}$-values and goodness-of-fit statistics. A chi-square goodness-of-fit test and four fit indices were used to assess model fit, including the Tucker-Lewis Index (TLI) [27], the comparative fit index (CFI) [28], the root mean square error of approximation (RMSEA) [29], and the standardized root mean square residual (SRMR) [30]. Because the chi-square test is highly sensitive to sample size and can lead to the rejection of well-fitting models, practical fit indices were emphasized [31]. Guidelines proposed by $\mathrm{Hu}$ and Bentler [32] suggest that models with TLI and CFI close to 0.95 or higher, RMSEA close to 0.06 or lower, and SRMR close to 0.08 or lower are representative of good-fitting models. A CFI of 0.90 or above [33] and an RMSEA of 0.08 or less [34], however, are also considered to represent reasonably acceptable model fit.

\subsubsection{Mortality prediction}

To assess the independent relationship between the General Depression factor and all-cause mortality 12 months post-AMI, regression models were carried out using Mplus. The $\mathrm{G}-\mathrm{S}-\mathrm{C}$ model was extended, and mortality status was regressed on the General Depression factor, controlling for known predictors of mortality (age, Killip class, and history of AMI). Regressing mortality status on the General Depression factor was done to estimate the association between depressive symptoms and mortality after removing variance from somatic and cognitive factors unrelated to depression. Only three covariates were used to avoid overfitting the prediction model because there were only 25 deaths in the first 12 months post-AMI [35]. Post hoc testing of additional variables was done by adding each additional predictor variable (sex, marital status, history of angina, diabetes, smoking) one at a time to the initially specified model to determine if the inclusion of these variables affected the relationship between mortality and the General Depression factor.

\section{Results}

\subsection{Sample characteristics}

A total of 477 AMI patients consented to participate, and 417 completed the BDI during their acute hospitalization with no missing items. As shown in Table 1, of the 417 patients included in the study, vital status was available for 416 , and $25(6.0 \%)$ died by 12 months post-AMI. Patients who died were significantly older $(P=0.016)$, more likely to have had a previous AMI $(P=0.002)$, and more likely to 
Table 1

Patient demographic and medical characteristics $(N=417)$

\begin{tabular}{lllll}
\hline & Number* & Percent & Mean SD \\
\hline Demographic variables & & & & \\
Age in yr (mean \pm SD) & & & 60.7 & 11.9 \\
Male & $313 / 417$ & 75.1 & & \\
Family income $>\$ 50,000$ & $167 / 365$ & 45.8 & & \\
Married & $323 / 412$ & 78.4 & & \\
Education high school or less & $279 / 410$ & 68.0 & & \\
Medical variables & & & & \\
Killip class $>1$ & $80 / 398$ & 20.1 & & \\
Previous MI & $94 / 417$ & 22.5 & & \\
History of angina & $97 / 417$ & 23.3 & & \\
Systolic blood pressure $>130 \mathrm{~mm} \mathrm{Hg}$ & $238 / 405$ & 58.8 & & \\
Diabetes mellitus & $89 / 387$ & 23.0 & & \\
Smoked in last 2 yr & $161 / 407$ & 39.6 & & \\
Symptoms of depression & & & & \\
BDI score (mean \pm SD) & & & 7.7 & 6.8 \\
BDI $\geqslant 10$ & $119 / 417$ & 28.5 & & \\
\hline
\end{tabular}

Abbreviation: MI, myocardial infarction.

* For some variables, the total $\mathrm{N}$ is $<417$ due to missing data.

have a history of angina $(P \leqslant 0.001)$. A higher percentage of patients who died within 12 months of the AMI had Killip class $>1$, although this was not statistically significant $(P=0.158)$. Mean total BDI scores were significantly higher for patients who died $(P=0.031)$, and there was a higher percentage, although nonsignificantly so $(P=0.077)$, of patients with $\mathrm{BDI} \geqslant 10$ among patients who died $(44.0 \%$ vs. $27.6 \%$ ).

\section{2. $C F A$}

Model fit statistics for each of the two models tested are shown in Table 2. The three-factor NA-PI-SD fit reasonably well based on fit indices. All factor loadings for the model were statistically significant with standardized loadings of 0.51 or higher for all items except item 19 (weight loss), for which the factor loading was 0.27 . The fit of the $\mathrm{G}-\mathrm{S}-\mathrm{C}$ model and the simplified $\mathrm{G}-\mathrm{S}-\mathrm{C}$ model was similar to that of the NA-PI-SD based on the fit indices, suggesting that the $\mathrm{G}-\mathrm{S}-\mathrm{C}$ model is a reasonable alternative to standard models. The total communalities attributable to the Anhedonia and Self-Criticalness factors were negligible $(<0.01 \%$ each) in the initial $\mathrm{G}-\mathrm{S}-\mathrm{C}$ model, and factor loadings were not statistically significant. There was no

Table 2

Summary of results from CFA

\begin{tabular}{llllllll}
\hline Model & $\chi^{2}$ & df & $P$ & CFI & TLI & RMSEA & SRMR \\
\hline NA-PI-SD & 145.9 & 75 & $<0.01$ & 0.96 & 0.98 & 0.05 & 0.07 \\
G-S-C & 143.2 & 74 & $<0.01$ & 0.96 & 0.98 & 0.05 & 0.06 \\
G-S-C simplified & 143.6 & 75 & $<0.01$ & 0.96 & 0.98 & 0.05 & 0.06 \\
\hline
\end{tabular}

Abbreviations: CFI, comparative fit index; TLI, Tucker-Lewis Index; RMSEA, root mean square error of approximation; SRMR, standardized root mean square residual; NA-PI-SD, Negative Attitude-Performance Difficulty-Somatic Elements; G-S-C, General-Somatic-Cognitive; CFA, confirmatory factor analyses. appreciable difference between the $\mathrm{G}-\mathrm{S}-\mathrm{C}$ model and the simplified $\mathrm{G}-\mathrm{S}-\mathrm{C}$ model in overall fit. Thus, results are presented here only for the simplified version. All factor loadings from the simplified $\mathrm{G}-\mathrm{S}-\mathrm{C}$ model were significant with the exception of the hypothesized loading of item 14 (physical appearance) on the Cognitive factor, so this item was removed from that factor. Item-factor specifications for the simplified $\mathrm{G}-\mathrm{S}-\mathrm{C}$ model are shown in the measurement model portion of Fig. 1. On the General Depression factor, loadings ranged from 0.45 (sexual disinterest) to 0.81 (past failure). The most salient factor loading on the Somatic factor was fatigue (0.61), with other factor loadings ranging from 0.22 (weight loss) to 0.50 (ability to work). Loadings on the Cognitive factor ranged from 0.21 (pessimism) to 0.53 (self-dislike). Item communalities were calculated for each item along with communality estimates for each factor that represented the proportion of total communality attributable to that factor (Table 3). As in Ward's results for the BDI-II, the General factor explained the highest proportion of total covariance (communality $=81 \%$ ) with the Somatic and Cognitive factors contributing modest amounts (9\% each). Item-factor loadings and other model data are available upon request from the corresponding author.

\subsection{Mortality prediction}

Fig. 1 shows the regression model in which $12-$ month mortality status is regressed on the General Depression factor, age, Killip class, and history of myocardial infarction. Path coefficients and the $R^{2}$-value from the model are provided in Table 4. The General Depression factor significantly predicted mortality at 12 months post-AMI $(P=0.009)$, controlling for age, Killip class, and history of AMI. History of AMI and history of angina were the only other variables that were significantly associated with death at 12 months. The fit indices indicated a reasonably good fit for the model: $T L I=0.94, C F I=0.91$, and RMSEA $=0.07$. The inclusion/exclusion of predictors not in the initially specified model (history of angina, sex, marital status, smoking) did not meaningfully alter the relationship between the General Depression factor and mortality. When the Somatic and Cognitive factors were similarly included as predictors of mortality post hoc, neither was significant. The Somatic factor was positively associated with mortality risk $(P=0.204)$ whereas the Cognitive factor was negatively related to mortality risk $(P=0.269)$.

\section{Discussion}

The main findings of this study were that (1) Ward's [21] $\mathrm{G}-\mathrm{S}-\mathrm{C}$ model for the BDI-II was successfully adapted for the original BDI and fit as well as or slightly better than a widely published, correlated three-factor model in a sample of patients hospitalized with AMI, and (2) the General 


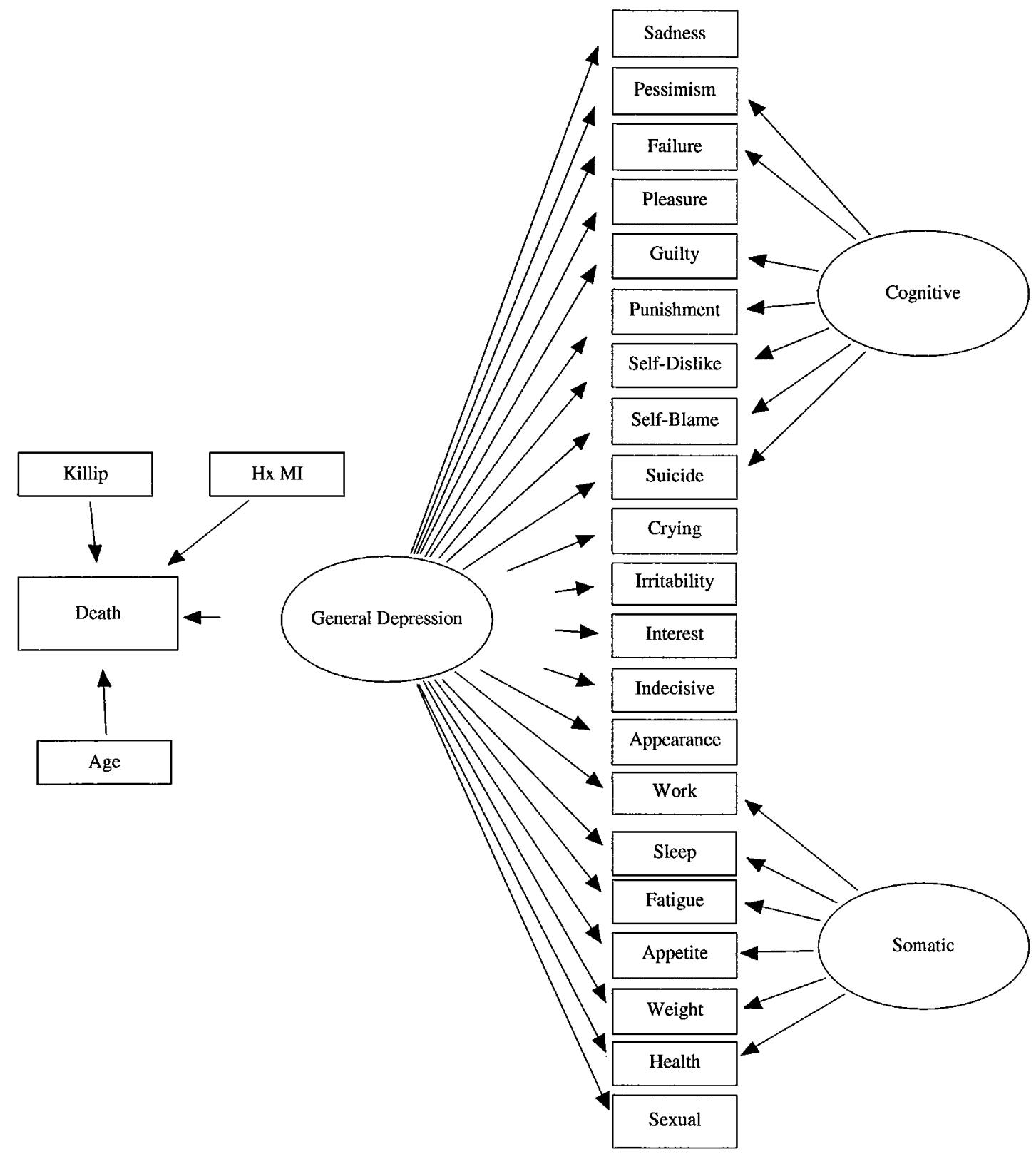

Fig. 1. Mortality status at 12 months regressed on the General Depression factor, age, Killip class, and history of myocardial infarction. In the $\mathrm{G}-\mathrm{S}-\mathrm{C}$ model, factors are uncorrelated, and item error variances are not shown.

Depression factor of the $\mathrm{G}-\mathrm{S}-\mathrm{C}$ model was a significant predictor of 12-month all-cause mortality in multivariate models even after potential measurement bias from somatic symptoms unrelated to depression was removed. The General factor of the $\mathrm{G}-\mathrm{S}-\mathrm{C}$ model accounted for $81 \%$ of total explained variance, which is within the range of $71-82 \%$ reported by Ward across five nonmedical samples. The Somatic and Cognitive factors each accounted for $9 \%$ of total explained variance, within the ranges of $6-11 \%$ (Somatic) and $8-14 \%$ (Cognitive) reported by Ward. The finding that $9 \%$ of explained variance in BDI scores was accounted for by somatic factors unrelated to depression indicates that, as suggested by several authors $[3,7,10-12]$, measurement of depressive symptoms with the BDI does pick up some variance related to somatic experience, but not depression. The amount of potential bias due to somatic symptoms, however, was small, and measurement bias did not explain the relationship between depressive symptoms and mortality. When variance from the Somatic symptom factor was removed from the measurement model with SEM techniques, symptoms of depression continued to predict mortality.

The Somatic symptom factor was positively related to mortality risk, whereas the Cognitive symptom factors were negatively related. These findings may be related to the likely meaning of the Somatic and Cognitive factors in the context of post-AMI hospitalization. The Somatic factor 
Table 3

Standardized factor loadings and communalities from the $\mathrm{G}-\mathrm{S}-\mathrm{C}$ model

\begin{tabular}{|c|c|c|c|c|c|}
\hline & Item & General & Somatic & Cognitive & $h^{2 \mathrm{a}}$ \\
\hline BDI 1 & Sadness & 0.79 & & & 0.62 \\
\hline BDI 2 & Pessimism & 0.78 & & 0.21 & 0.66 \\
\hline BDI 3 & Past failure & 0.81 & & 0.35 & 0.78 \\
\hline BDI 4 & Loss of pleasure & 0.81 & & & 0.65 \\
\hline BDI 5 & Guilty feelings & 0.79 & & 0.22 & 0.68 \\
\hline BDI 6 & Punishment feelings & 0.57 & & 0.49 & 0.57 \\
\hline BDI 7 & Self-dislike & 0.76 & & 0.53 & 0.86 \\
\hline BDI 8 & Self-blame & 0.65 & & 0.51 & 0.68 \\
\hline BDI 9 & Suicidal ideation & 0.80 & & 0.32 & 0.75 \\
\hline BDI 10 & Crying & 0.72 & & & 0.51 \\
\hline BDI 11 & Irritability & 0.51 & & & 0.26 \\
\hline BDI 12 & Withdrawal & 0.76 & & & 0.57 \\
\hline BDI 13 & Indecisiveness & 0.78 & & & 0.60 \\
\hline BDI 14 & Physical appearance & 0.59 & & & 0.34 \\
\hline BDI 15 & Ability to work & 0.55 & 0.50 & & 0.54 \\
\hline BDI 16 & Sleep problems & 0.56 & 0.25 & & 0.38 \\
\hline BDI 17 & Fatigue & 0.56 & 0.61 & & 0.68 \\
\hline BDI 18 & Appetite & 0.53 & 0.35 & & 0.41 \\
\hline BDI 19 & Weight loss & 0.16 & 0.42 & & 0.20 \\
\hline BDI 20 & Concerns about health & 0.51 & 0.22 & & 0.31 \\
\hline \multirow[t]{2}{*}{ BDI 21} & Sexual disinterest & 0.45 & & & 0.20 \\
\hline & Communality $^{\mathrm{a}}$ & 0.81 & 0.09 & 0.09 & \\
\hline
\end{tabular}

a Communality $\left(h^{2}\right)$ for each factor is the proportion of total communality that is attributable to the factor.

was dominated by items related to fatigue and loss of energy, both of which are commonly experienced during hospitalization for AMI and which may or may not be related to depression. Variance from items on the Cognitive factor may take on special meaning in the context of an AMI given the predominance of self-blame on the Cognitive factor. Cognitive theories of depression [36] associate self-blame with poor adjustment. On the other hand, studies of the consequences of illness attributions among patients with medical illness [37] suggest that self-blame or attribution of consequences to one's own behavior may be related to more positive coping and better subsequent outcomes [38]. These two theoretical models may be addressing two distinct constructs, characterological and behavioral self-blame, however. Whereas characterological or personality-related self-blame would be expected to be maladaptive, behavioral self-blame may be a useful coping strategy after an acute medical event that provides a sense of controllability of the future and over one's own health and a motivation to behavior change [38].

As reviewed by Ward [21], in addition to essentially equal fit to the data, the orthogonal $\mathrm{G}-\mathrm{S}-\mathrm{C}$ model for the BDI has several advantages over correlated-factor models. Many different correlated-factor models for the BDI have been reported. Correlated models tend to produce highly correlated factors that provide only limited discriminant validity. Because of the high factor correlations, itemfactor allocations often vary substantially across samples, which limits their substantive interpretability $[21,39]$. In addition, the NA-PI-SD model for the BDI does not provide clear theoretical coherence, and several items are not easily described as either purely somatic or performance related. The $\mathrm{G}-\mathrm{S}-\mathrm{C}$ model, on the other hand, has been shown to provide a stable fit that is as good or better than the correlated-factor models across several different samples, including the sample of AMI patients in this study using an adapted version for the BDI. Interpretation of the G-S-C is also consistent with the use of a single summary score to estimate the severity of depressive symptoms as described by Beck et al. [40]. On the other hand, one potential advantage of a correlated-factor model is that the degree of relationship between somatic and nonsomatic elements is built into the model.

In the context of post-AMI depression, the most important advantage of the $\mathrm{G}-\mathrm{S}-\mathrm{C}$ is that it allows for prediction of outcomes, such as mortality, free from bias from somatic symptoms that are unrelated to depression per se. Mortality prediction with SEM of the $\mathrm{G}-\mathrm{S}-\mathrm{C}$ has important advantages over the approaches used in the two previous studies that have addressed this issue. Irvine et al. [3] used cognitive symptoms alone to predict mortality. That approach, however, may be overly restrictive and may in some cases fail to detect valid depression-mortality links because it removes all somatic items, and somatic symptoms are central to the experience of depression for many patients, regardless of medical illness $[41,42]$. The $\mathrm{G}-\mathrm{S}-\mathrm{C}$ approach used in this study, on the other hand, allows variance from the somatic items to load on the General Depression factor and, thus, includes them in the latent predictor variable, excluding only systematic variance from the somatic items that is unrelated to the General Depression factor. de Jonge et al. [11] used exploratory factor analysis techniques to assess whether measurement bias influences the relationship between symptoms of depression as measured by the BDI and cardiac outcomes. They regressed the cardiac outcomes variable on both the cognitive and the somatic factors of a traditional two-factor correlated model. This method, however, would not be expected to differentiate well between cognitive and somatic factors because several items loaded on both factors and the high correlation between the factors $(>0.70)$ may lead to problems with multicollinearity in regression models [43,44]. Although many items in the present study loaded on two factors, the factors were uncorrelated, which allowed for explicit isolation of variance on somatic items that were not related to the General Depression factor.

There are limitations in our study that should be acknowledged. The study had a moderate-sized patient population and a relatively small number of total mortalities. Mortality data did not include whether or not death was cardiac related and were collected via report of patients' family members, general practitioners, or specialist physicians, the accuracy of which has not been demonstrated. Adjustment for confounders only included age, Killip class, and a history of AMI. Other potentially important confounders, such as sociodemographic factors, indicators of AMI 
Table 4

Path coefficients and $R^{2}$-value for structural equation model regression of 12-month mortality on the General Depression factor and covariates

\begin{tabular}{lccc}
\hline Variable & Path coefficient & $P$-value & $R^{2}$ \\
\hline 12-month mortality status & & & 0.221 \\
General Depression factor & 0.295 & 0.009 & \\
Age & 0.015 & 0.128 & \\
History of MI & 0.717 & 0.001 & \\
Killip class > & 0.307 & 0.210 & \\
History of angina $^{\mathrm{a}}$ & 0.672 & 0.005 & \\
Male $^{\mathrm{a}}$ & 0.050 & 0.859 & \\
Married $^{\mathrm{a}}$ & -0.300 & 0.261 & \\
Smoked in last 2 $\mathrm{yr}^{\mathrm{a}}$ & -0.002 & 0.994 & \\
Somatic factor $^{\mathrm{a}}$ & 0.188 & 0.204 & \\
Cognitive factor $^{\mathrm{a}}$ & -0.159 & 0.269 & \\
\hline
\end{tabular}

${ }^{\text {a }}$ Each variable added to core predictors (General Depression factor, age, history of MI, Killip class) individually.

severity (e.g., left-ventricular ejection fraction), comorbid conditions, and hospital course were not measured, but should be included in future studies that use these methods. In addition, we used a probit structural equation model rather than a survival model, because time to death was not available and because this is not an option in SEM of latent variables with programs such as Mplus. On the other hand, SEM paradigms allow for much greater sophistication in modeling sources of variance within and across items that cannot be implemented with traditional survival models.

It is not clear how the findings of this study would apply to other widely used depression symptom assessment instruments, such as the Center for Epidemiological Studies Depression Scale (CES-D) [45], the Hamilton Rating Scales for Depression (HRSD) [46], or the Patient Health Questionnaire-9 (PHQ-9) [47]. Although the CES-D, HRSD, and PHQ-9 have generally similar emphases on somatic or vegetative symptoms (seven of 20 items on the CES-D, four of 14 on the HRSD, and four of nine on the PHQ-9) [48], a similar exercise would need to be conducted for each instrument to determine the degree to which findings from this study would replicate.

In summary, the $\mathrm{G}-\mathrm{S}-\mathrm{C}$ model provides a reasonably good-fitting explanation of BDI data from patients hospitalized with AMI that is as good as or better than model fit with an alternative three-factor model. The $\mathrm{G}-\mathrm{S}-\mathrm{C}$ model has important theoretical and practical advantages, including the ability to model the relationship of a General Depression factor with mortality after explicitly removing variance from somatic factors unrelated to the General Depression factor. When this model was implemented, controlling for important demographic and medical variables, the General Depression factor significantly predicted 12-month all-cause mortality in a sample of 417 post-AMI patients.

\section{Acknowledgments}

This research was conducted with funds from the Heart and Stroke Foundation of Ontario and the Samuel
Lunenfeld Foundation of Toronto, Ontario awarded to Dr. Stewart and Dr. Abbey. Dr. Grace receives funding from the Canadian Institutes of Health Research, and Dr. Ziegelstein is supported by NIH/NINDS R21 NS048593. We also are grateful to Linda Green for her diligence in study coordination.

\section{References}

[1] Lesperance F, Frasure-Smith N, Talajic M, Bourassa MG. Five-year risk of cardiac mortality in relation to initial severity and one-year changes in depression symptoms after myocardial infarction. Circulation 2002;105:1049-53.

[2] Bush DE, Ziegelstein RC, Tayback M, Richter D, Stevens S, Zahalsky $\mathrm{H}$, et al. Even minimal symptoms of depression increase mortality risk after acute myocardial infarction. Am J Cardiol 2001;88:337-41.

[3] Irvine J, Basinski A, Baker B, Jandciu S, Paquette M, Cairns J, et al. Depression and risk of sudden cardiac death after acute myocardial infarction: testing for the confounding effects of fatigue. Psychosom Med 1999:61:729-37.

[4] Carney RM, Blumenthal JA, Catellier D, Freedland KE, Berkman LF, Watkins LL, et al. Depression as a risk factor for mortality after acute myocardial infarction. Am J Cardiol 2003;92:1277-81.

[5] Lane D, Carroll D, Ring C, Beevers DG, Lip GY. Mortality and quality of life 12 months after myocardial infarction: effects of depression and anxiety. Psychosom Med 2001;63:221-30.

[6] Mayou RA, Gill D, Thompson DR, Day A, Hicks N, Volmink J, et al. Depression and anxiety as predictors of outcome after myocardial infarction. Psychosom Med 2000;62:212-9.

[7] Sorensenf C, Friis-Hasche E, Haghfelt T, Bech P. Postmyocardial infarction mortality in relation to depression: a systematic critical review. Psychother Psychosom 2005;74:69-80.

[8] van Melle JP, de Jonge P, Spijkerman TA, Tijssen JG, Ormel J, van Veldhuisen DJ, et al. Prognostic association of depression following myocardial infarction with mortality and cardiovascular events: a meta-analysis. Psychosom Med 2004;66:814-22.

[9] Nicholson A, Kuper H, Hemingway H. Depression as an aetiologic and prognostic factor in coronary heart disease: a meta-analysis of 6362 events among 146538 participants in 54 observational studies. Eur Heart J 2006;27:2763-74.

[10] Lane D, Carroll D, Lip GY. Anxiety, depression, and prognosis after myocardial infarction: is there a causal association? J Am Coll Cardiol 2003;42:1808-10.

[11] de Jonge $P$, Ormel $J$, van den Brink RH, van Melle JP, Spijkerman TA, Kuijper A, et al. Symptom dimensions of depression following myocardial infarction and their relationship with somatic health status and cardiovascular prognosis. Am $\mathbf{J}$ Psychiatry 2006; $163: 138-44$.

[12] Mendes de Leon CF. Depression and social support in recovery from myocardial infarction: confounding and confusion. Psychosom Med 1999;61:738-9.

[13] Koenig HG, Cohen HJ, Blazer DG, Krishnan KR, Sibert TE. Profile of depressive symptoms in younger and older medical inpatients with major depression. J Am Geriatr Soc 1993;41:1169-76.

[14] Cavanaugh S, Clark DC, Gibbons RD. Diagnosing depression in the hospitalized medically ill. Psychosomatics 1983;24:809-15.

[15] Thombs BD, Bass EB, Ford DE, Stewart KJ, Tsilidis KK, Patel U, et al. Prevalence of depression in survivors of acute myocardial infarction. J Gen Intern Med 2006;21:30-8.

[16] Brown-DeGagne AM, McGlone J, Santor DA. Somatic complaints disproportionately contribute to Beck Depression Inventory estimates of depression severity in individuals with multiple chemical sensitivity. J Occup Environ Med 1998;40:862-9. 
[17] Leentjens AF, Verhey FR, Luijckx GJ, Troost J. The validity of the Beck Depression Inventory as a screening and diagnostic instrument for depression in patients with Parkinson's disease. Mov Disord 2000;15:1221-4.

[18] Mohr DC, Goodkin DE, Likosky W, Beutler L, Gatto N, Langan MK. Identification of Beck Depression Inventory items related to multiple sclerosis. J Behav Med 1997;20:407-14.

[19] Moran PJ, Mohr DC. The validity of Beck Depression Inventory and Hamilton Rating Scale for Depression items in the assessment of depression among patients with multiple sclerosis. J Behav Med $2005 ; 28: 35-41$.

[20] Sliwinski M, Gordon WA, Bogdany J. The Beck Depression Inventory: is it a suitable measure of depression for individuals with traumatic brain injury? J Head Trauma Rehabil 1998;13:40-6.

[21] Ward LC. Comparison of factor structure models for the Beck Depression Inventory-II. Psychol Assess 2006;18:81-8.

[22] Grace SL, Abbey SE, Pinto R, Shnek ZM, Irvine J, Stewart DE. Longitudinal course of depressive symptomatology after a cardiac event: effects of gender and cardiac rehabilitation. Psychosom Med 2005;67:52-8.

[23] Beck AT, Steer RA. Manual for the revised Beck Depression Inventory. San Antonio, TX: Psychological Corporation; 1987.

[24] Beck AT, Steer RA, Garbin MG. Psychometric properties of the Beck Depression Inventory: twenty-five years of evaluation. Clin Psychol Rev 1988;8:77-100.

[25] McDonald RP, Ringo Ho M. Principles and practice in reporting structural equation analyses. Psychol Methods 2002;7:64-82.

[26] Muthén LK, Muthén BO. Mplus user's guide. 3rd edition. Los Angeles, CA: Muthén \& Muthén; 1998-2004

[27] Tucker LR, Lewis C. A reliability coefficient for maximum likelihood factor analysis. Psychometrika 1973;38:1-10.

[28] Bentler PM. Comparative fit indexes in structural models. Psychol Bull 1990;107:238-46.

[29] Steiger JH. Structural model evaluation and modification: an interval estimation approach. Multivar Behav Res 1990;25:173-80.

[30] Bentler PM, Wu EJC. EQS structural equations program. Version 6.1 2003.

[31] Reise SP, Widaman KF, Pugh RH. Confirmatory factor analysis and item response theory: two approaches for exploring measurement invariance. Psychol Bull 1993;1 14a:552-66.

[32] Hu L, Bentler PM. Cutoff criteria for fit indexes in covariance structure analysis: conventional criteria versus new alternatives. Struct Equ Model 1999;6:1-55.
[33] Kline RB. Principles and practice of structural equation modeling. 2nd edition. New York: Guilford Press; 2005.

[34] Browne MW, Cudeck R. Alternative ways of assessing fit. In: Bollen KA, Long JS, editors. Testing structural equation models. Newbury Park, CA: Sage; 1993. p. 136-62.

[35] Babyak MA. What you see may not be what you get: a brief, nontechnical introduction to overfitting in regression-type models. Psychosom Med 2004;66:411-21.

[36] Beck AT. Depression: Clinical, experimental, and theoretical aspects. New York: Harper and Row; 1976.

[37] Leventhal H, Leventhal EA, Contrada RJ. Self-regulation, health, and behavior: a perceptual-cognitive approach. Psychol Health 1998;13: 717-33.

[38] Hall S, French DP, Marteau T. Causal attributions following serious unexpected negative events: a systematic review. J Soc Clin Psychol $2003 ; 22: 515-36$.

[39] Steer RA, Ball R, Ranieri WF, Beck AT. Dimensions of the Beck Depression Inventory-II in clinically depressed outpatients. J Clin Psychol 1999;55:117-28.

[40] Beck AT, Steer RA, Brown GK. Manual for the Beck Depression Inventory-II. San Antonio, TX: Psychological Corporation; 1996.

[41] Kirmayer LJ, Robbins JM. Patients who somatize in primary care: a longitudinal study of cognitive and social characteristics. Psychol Med 1996;26:937-51.

[42] Simon GE, VonKorff M, Piccinelli M, Fullerton C, Ormel J. An international study of the relation between somatic symptoms and depression. N Engl J Med 1999;341:1329-35.

[43] Thombs BD, Grace SL, Ziegelstein RC. Do symptom dimensions of depression following myocardial infarction relate differently to physical health indicators and cardiac prognosis? Am J Psychiatry 2006;163:1295-6.

[44] de Jonge P. Dr. de Jonge and colleagues reply. Am J Psychiatry 2006;163:1296.

[45] Radloff LS. The CES-D scale: a self-report depression scale for research in the general population. Appl Psychol Meas 1977;1: $385-401$.

[46] Hamilton M. Development of a rating scale for primary depressive illness. Br J Soc Clin Psychol 1967;6:278-96.

[47] Kroenke K, Spitzer RL, Williams JB. The PHQ-9: validity of a brief depression severity measure. J Gen Intern Med 2001;16:606-13.

[48] Shafer AB. Meta-analysis of the factor structures of four depression questionnaires: Beck, CES-D, Hamilton, and Zung. J Clin Psychol 2006;62:123-46. 